\section{MULTIPLE PARASITISM OF BREWER'S BLACKBIRD NEST}

VIC HARPER, R.R. 2, Saskatoon, Saskatchewan S7K 3 V5

Brewer's Blackbirds nest freely in our hedges and windbreaks, mostly in deciduous shrubs but occasionally in young spruce. About $10 \%$ of the nests contain a cowbird egg.

The Prairie Nest Records Scheme data up to mid -1975 reveals that of the records of 371 nests of Brewer's Blackbirds there were 85 instances or $22.9 \%$ of parasitism by Brown-headed Cowbirds.

On 3 June 1979 I found a Brewer's
Blackbird nest $1.5 \mathrm{~m}$ from the ground in a High-bush Cranberry. It contained one egg. The next day there were three, one of which was a cowbird's. Next day there were six, three of which were cowbirds' and next day I found ten, six of them being cowbird eggs. The blackbird had started incubation.

Thinking this very unusual I monitored the nest every second day and the count remained the same. On the 13th day of incubation I found them all hatched. Eight days later I had to remove some chicks in order to take the census - they were all accounted for and looked healthy and happy. The nest was so full that I refrained from further enumeration for fear that some might fledge prematurely. I feel that all eventually fledged successfully.

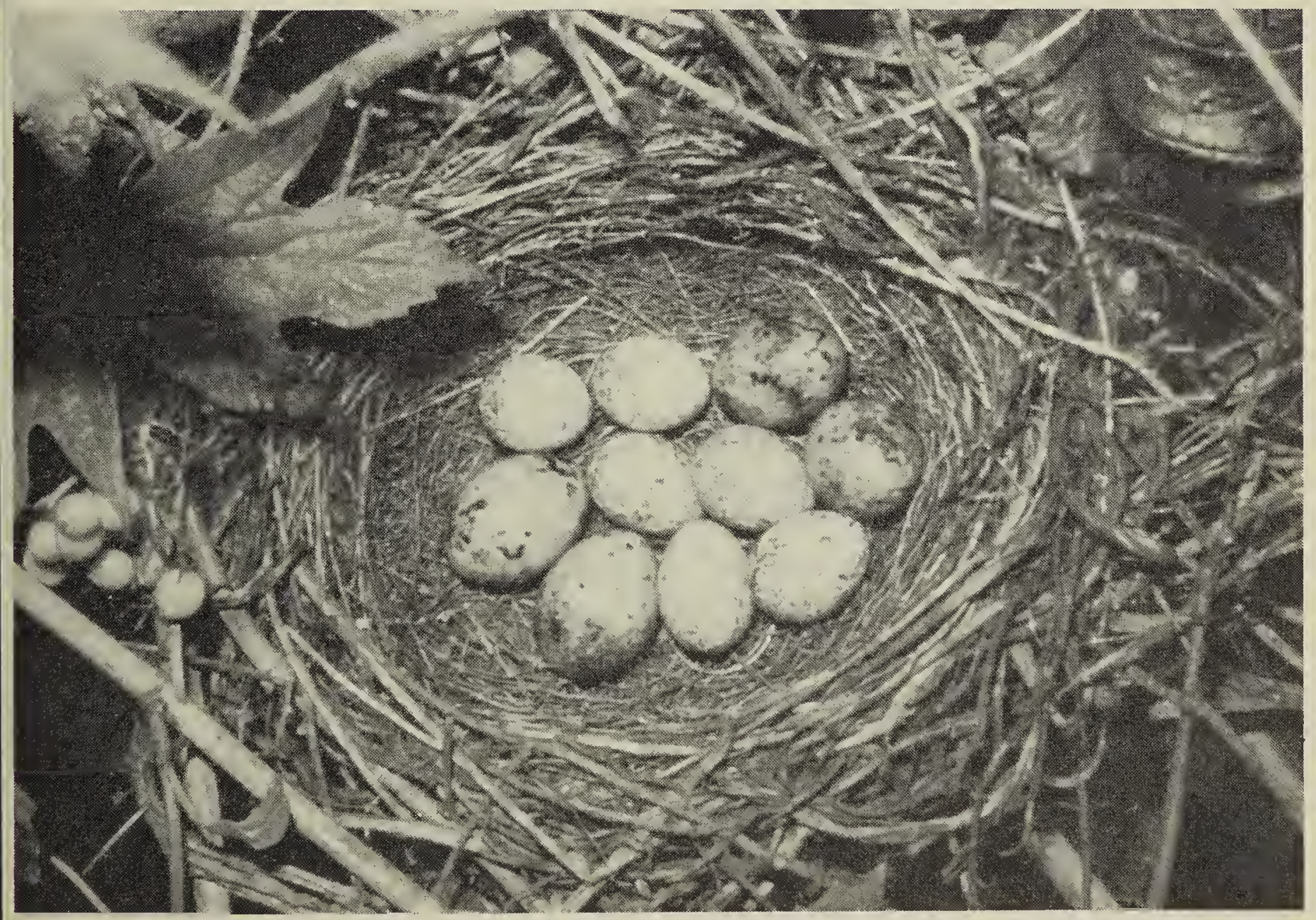

Brewer's Blackbird nest

Vic Harper 